\title{
Physical Education Reform in Colleges and Universities based on Talents Training
}

\author{
Ye Liu ${ }^{1}$, Ping Liu
}

1, 2pingxiang university,pingxiang,jiangxi,337055,China.

Key words: Basic education; Curriculum reform; Education talents training

Abstract.

Through the research on the development trend of physical education reform and the cultivation of $\mathrm{PE}$ talents in colleges and universities, it is found that the teaching content of physical education curriculum is single and athletic consciousness is strong. Therefore, in the reform of college physical education, we should pay attention to dilute athletic consciousness and emphasize that the guiding ideology of PE is physical health. This paper puts forward the problems existing on the reform of college physical education and talents training, and tries to solve the problems and realize the real purpose of college sports reform, which is cultivating talents.

Now the society is in an era of common development of knowledge, technology and economy, and people's constant pursuit of knowledge has made the world science and technology and market economy continue to progress. Because of the continuous development of social economy, people pay more and more attention to culture, which forces us to re-examine the cultivation of talents in the process of university education reform. A new round of curriculum reform not only affects the traditional basic teaching, but also changes the objectives adjustment of higher education in talents training. How to better to adapt to the reform of college physical education is the key to talents training. Physical education workers are thinking that whether changing traditional sports education courses has a great impact on the cultivation of talents, and whether the impact is a good trend or a wrong choice. This is a very difficult problem. [1-2] The cultivation of a talent is certainly inseparable from school education. The amount of knowledge students master, the quality, and acceptance ability are school's educational ideas and the dominant direction, which reflect the school's work framework and teaching concepts.

Training model is neither the content of teaching nor the simple expression form. It is a process concept with no purpose and no result. Training mode is only a process of teaching design and environment construction. It is also the overall expression of talents cultivation. Under the background of different times, social cultural technology is also different. The cultivation of talent quality refers to the continuous optimization of talents training model. In the era of common development of knowledge, science and technology and economy, the characteristic of this era is knowledge-based, innovation-oriented and people-oriented. This is an important criterion for cultivating talents. [3-4] To know whether the training of college physical education in colleges and universities meets the needs of social development and modern society for sports talents, physical education professional training model reforms must be carried out. Therefore, the reform of physical education talents training mode and the re-establishment of educational content are the best choices to strengthen the adaptation of contemporary physical education in the era of education popularization. This is a key position for newly reformed physical education, and also an important part in the research of physical education reforms development trend and higher education institutions physical education talents training. 


\section{Problems of Physical Education Reform and talents Training in Colleges and Universities}

With the development and progress of society, the modernization degree of sports professionals has been improved. The society needs not only physical education teachers and athletic athletes, but also sports talents for sports economy and sports management. The cultivation of college sports talents is a systematic process, which includes education mode, curriculum setting, and teaching evaluation and so on. At present, China's higher physical education institutions' talents training models are based on physical education as the main body, sports curriculum as the leading, and physical education teachers training as the goal, which is a closed system of clear traditional sports talents training characteristics. There is a clear imbalance between this kind of sports talents training objectives and training structure and social needs. Due to the shortage of existing professionals in China, China needs to introduce high-level talents from abroad.

According to statistics, only 17 percent of China's physical education teachers have a master's degree, of which doctorate is even less. There is a serious gap between the national requirements of higher education teachers which is 30 percent master's degree. We are too single for the training of high-level professionals, and the curriculum content is old-fashioned. In teaching, we put too much emphasis on theory and ignore the practice with a lack of innovation and ignoring market effect. These have a direct impact on our high-level sports professionals' training quality. With society progress, we should appropriately expand new majors and improve old majors to effectively expand undergraduate and graduate teaching. Expand the types of sports talents and enhance the quality of sports talents. Also pay attention to the concept of competitive talents training, market-oriented concept and the concept of internationalization. Cultivate sports professionals with exploring innovation spirit and working ability, conforming to social practice and social development needs. In addition, we should strengthen the construction of teachers' strength in higher physical education colleges and create better environment to cultivate high-level talents for our country.

\section{Development Trend of Physical Education Talents Training in Colleges and Universities}

Now in the era of common development of knowledge, technology and economy, people's constant pursuit of knowledge has made the world's science and technology and market economy continue to progress. People's living standards continue to be improved and social economy has continuous development. People pay more and more attention to culture, which forces us to re-examine the cultivation of talents in the process of university education reform. Physical education is the most enjoyable one in all disciplines to relax the students, shouldering the responsibility for students' health, so a good guiding ideology is very important for physical education. Physical and mental health, good quality and strong athletic ability are the dominant thoughts of physical education teaching. The new round of curriculum reform mainly takes the correct method teaching students' physical and mental health development and sports technology as the center, transformation and innovation of teaching projects as the purpose, and students' sports project innovation and development as purpose. The teaching content of national characteristics is also selected as teaching content in the classroom. Students are very fond of sports which are consistent with world culture. If these courses are written into the course of physical education, physical education class will become enriching. New reform of physical education model needs students' wholehearted investment and no longer previous competitive sports courses, so for every student, this is a fresh thing. This kind of teaching can inspire students' interest and make the students more actively accept the course.

Adjusting traditional sports curriculum and paying attention to the development of new courses. The previous sport curriculum is relatively simple and competitive, which results in that 
physical education curriculum are not fully played in training talents. A new round of curriculum reform not only affects traditional basic teaching, but also changes higher education talents training objectives adjustment. How to better to adapt to college physical education reform is the key to talents training, and physical education workers are thinking of the problem as whether the change of traditional sports education courses has a great impact on talents cultivation. Whether the impact is a good trend or a wrong choice, this is a very difficult problem. Therefore, we have to improve these problems of the curriculum reform as a start, and the improvement direction is mainly based on students' physical and mental health development and correct sports technology teaching way to transform and make innovation of teaching projects as a purpose and take students' innovation and development in sports as the purpose. The teaching content of national characteristics is also selected as teaching content in the classroom. Students are very fond of sports that are consistent with the world culture. If these courses are written into the course of physical education, physical education class will become enriching.

After the reform, teachers have developed six learning areas, which are: project participation, body quality, exercise ability, communication skills, communication ways, and mental health. These six areas constitute two lines. The first is physical practice line, mainly athletic ability to participate in and the second is body health, mainly the embodiment of social capacity. The improvement of physical education curriculum in colleges and universities is an important cognition of relationship talents training and the need of educational curriculum reform. At present, the curriculum of physical education in colleges and universities is to develop the curriculum foundation of physical education in the curriculum of basic teaching, and rapidly adjust theoretical courses and technical courses. College sports professional courses should pay more attention to its mixing series so that the curriculum may develop more perfectly.

Putting focus on physical education teachers' teaching norms on students. From a school's teaching level, it is able to see the school's teachers' quality. Teachers must have clear language and teach properly in course teaching so that students can take the initiative to actively participate in the activities. To be a qualified sports teacher, one should have professional sports knowledge and skills in teaching, and slowly play down competitive sports in the course, as long as students can learn the knowledge needs later in physical education curriculum. To be a good sports teacher, one need to have different skills in teaching concept and pay more emphasis on popularity, make convergence of curriculum content and the world trend, as well as role exchanging. Take themselves as students, and feel the charm of physical education from the student's point of view. Analyze the characteristics of students and their ability to accept the course from the results of teaching. As a sports teacher, one will always pay attention to every student's learning methods, and find out the key points which can stimulate students' interest.

Cultivating students' interests in physical education. Cultivate students' will and improve students' interest in sports. Will is associated with the meaning of life and a person's acceptance of new things which reflects his ability. New curriculum reform is to distinguish the level of a person's ability to accept fresh things. But this is not to explain a person's IQ level, but highlights the students' ability to make progress. In this new round of reform process, students will find themselves, compared with the past, more capable to adapt to the community with better physical quality and more mental health. A good body is the goal everyone pursuits, so during school, students should try to develop a good habit, and this habit may accompany their whole life. Traditional physical education did not pay attention to the cultivation of students' interests, resulting in many students' loss of exercise consciousness before leaving school. College sports teachers in the usual teaching time should pay more attention to the application of various fresh teaching 
methods so that the classroom atmosphere would become relaxed and happy. Promote students to exercise more than usual and enhance self-confidence. A reasonable teaching atmosphere is the key to cultivating students' interest in physical education.

\section{Physical Education Reform to complete talents training in Colleges and Universities}

It is necessary to improve the reform of physical education and the training programs of PE talents for colleges and universities by attaching importance to the feedback of basic teaching and the training of teachers. Whether they can teach students for different age structure, whether they can control the teaching atmosphere, and whether they can instill knowledge they have learned to students are the problems need to think about by higher physical education teachers. In the development of sound physical education reform and higher education training programs, invite some teachers with excellent teaching experience or engaging in the occupation of education managers to participate so that we can better discuss the reform of physical education and training program for physical education talents in colleges and universities and perfect teaching system. Finally, in order to improve the good communication effect of physical education reform and physical education talents cultivation in colleges and universities, the interaction between teachers is essential. Workers engaging in education industry should take the initiative to take the responsibility for physical education reform and talents cultivation in physical education in colleges and universities.

\section{Conclusion}

There are still a lot of problems to be solved in the development trend of physical education reform and the cultivation of college physical education talents. Sport is a discipline related to students' physical and physical health, which is different from other teaching models. In other disciplines, students have some interest problems in learning, which dispels the enthusiasm for learning. This is when physical education is particularly important. We should pay more attention to the improvement in physical education curriculum and the quality of teachers, take different modes of exercise considering different physical fitness of students, and find out the effective way to improve physical education models by understanding current trend of physical education reform development and sports education talents training. We can see that college physical education is very important to the training of talents.

\section{References}

[1] Fan Shujiao. Connection research on physical education major curriculum design and physical education curriculum reform in elementary education [D]. Zhengzhou: Zhengzhou University, 2010.

[2] Zhao Haiying. Interactive development research on physical education curriculum system and basic physical education reform in Guizhou province [D]. Guiyang: Guizhou Normal University, 2009.

[3] Ma Haitao. Research on basic education curriculum reform and physical education major talents cultivation in colleges and universities [J]. Journal of Xi'an Institute of Physical Education, 2010 (3): 371.

[4] Gao Qingang, Wang Lei. Progress research on the relationship between physical education major talents training and PE curriculum reform in elementary education [J]. Journal of Huaibei 
Vocational and Technical College, 2010 (6): 68 